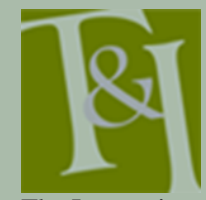

The International Journal for Translation \& Interpreting Research trans-int.org

\title{
Deaf and non-deaf research collaboration on Swiss German Sign Language (DSGS) interpreter training in Switzerland
}

\author{
Patty Shores \\ HfH University of Applied Sciences of Special Needs Education, Sign-Language Interpreting, \\ Zurich \\ patty.shores@hfh.ch
}

Christiane Hohenstein

ZHAW Zurich University of Applied Sciences, School of Applied Linguistics

christiane.hohenstein@zhaw.ch

\section{Joerg Keller}

ZHAW Zurich University of Applied Sciences, School of Applied Linguistics

joerg.keller@zhaw.ch

DOI: ti.106201.2014.a03

\begin{abstract}
Teaching, training, and assessment for sign language interpreters in Swiss German sign language (DSGS) developments since 1985 have resulted in the current Bachelor level at the Zurich University of Applied Sciences, Special Needs Education $(\mathrm{HfH})$. More recently, co-teaching with Zurich University of Applied Sciences, School of Applied Linguistics (ZHAW) non-deaf linguists in linguistics and intercultural competence training has led to Deaf and non-deaf research collaboration.

At present, there are considerable skills gaps in student proficiency in DSGSinterpreting. Standards that evaluate student second language competencies in DSGS do not yet exist for those who graduate from training programs. Despite DSGS being taught by Deaf sign language instructors, socio-linguistic and pragmatic standards reflecting the practices of the Deaf community are lacking in hearing second language learners. This situation calls for community based research on the linguistic practices embedded in the DSGS community and its domains. The ongoing need for research is to adapt unified standards according to the Common European Reference Frame (CEFR) and the European Language Portfolio (ELP) describing learners' abilities and competencies, rather than deficiencies.

A pilot project compiling existing DSGS teaching materials was carried out by Deaf SL instructors together with non-deaf linguists under auspices of the Swiss Federation of the Deaf (SGB-FSS), HfH Zürich and ZHAW. The findings show at threshold level (A1-A2) a considerable amount of subjects related to pragmatic and intercultural aspects of DSGS not listed in the teaching materials, nor part of CEFR descriptors. Consequently, a community-based project including Deaf and non-deaf researchers was proposed and is under way. With the cooperation of the current European project, PRO-Sign, the project focuses on identifying those aspects of sign language where descriptors of competencies are substantially different from spoken languages. Results from this project will permit the development of unified teaching materials, of standardised assessments and provide a basis not only for purposes of foreign language learning and interpreter training, but also help to foster the development of a CEFR for Sign Languages in Europe.
\end{abstract}

Keywords. Research collaboration with Deaf and non-deaf; sign language learning, teaching and assessment with CEFR 


\section{Introduction and background}

Switzerland holds a unique position among the highly developed economies and democracies of Europe: It is situated outside the European Union (EU), yet strongly influences EU policies, and has especially influenced the development of the Common European Framework of Reference for Languages in learning, teaching and assessment (CEFR, cf. section 2).

Switzerland has one of the most progressive language legislations within Europe, recognizing four official languages (German, French, Italian and Romansh), yet has not yet ratified the UN Convention on the Rights of Persons with Disabilities (UN 2008-2012). In fact, Zurich, since $2005^{1}$, is the only German speaking canton in Switzerland where sign language, in particular the Swiss German Sign Language (Schweizerdeutsche Gebärdensprache, DSGS $)^{2}$, is officially recognised, with a statement of inclusion of sign language in the constitution (Kanton Zürich, 2005, Art.12).

Moreover, teaching, training, and assessment for sign language interpreters in DSGS has been developed on an ongoing basis since 1985 towards the current Bachelor level at the HfH Zurich (University of Applied Sciences: Special Needs Education Zurich). As of 2011, both the Swiss German sign language instructor training program (AGSA) and the Swiss German sign language interpreter training program (GSD) celebrated their anniversaries of 20 and over 25 years, respectively (Haug \& Shores, 2011). At the same time, a history of more than 30 years of sign language research since 1980 in the Swiss German sign language community has been realised (Boyes Braem et al., 2012).

Traditionally, DSGS introductory and intermediate level courses are offered by the Swiss German section of the Swiss Federation of the Deaf $\left(\right.$ SGB-FSS ${ }^{3}$ ). They are taught by DSGS instructors trained and qualified by SGB-FSS and HfH AGSA. Students interested in being trained as DSGS interpreters need an average of 120 introductory hours of sign language and cultural studies prior to admission to the Bachelor level interpreter education program. During the three-year full time, or four year part time program, the students continue to receive training in formal sign language and culture. Cultural learning opportunities designed to enhance further understanding of Deaf culture are also acquired through cultural internships and the interpreting training courses.

Over the past five years, lecturers from ZHAW School of Applied Linguistics specializing in linguistics, interpreting and intercultural communication have been included in the HfH DSGS interpreter training curriculum. Co-teaching has made it possible to discuss students' particular difficulties with regard to both Deaf culture and linguistic features of sign language and its use. Pragmatics of communication among Deaf and hearing people, as well as sociolinguistic aspects like register usage and politeness, were cases in point where, as an outcome of co-teaching between Deaf instructors and non-deaf linguists, the need for joint projects was recognised.

In particular, the shift toward a policy of lifelong learning and the introduction of the Common European Framework of Reference (CEFR) for language learning, teaching, and assessment necessitate new learning and teaching methods, as well as new self-assessment tools. This situation has led to a deaf-non-deaf research collaboration, the focus of which is on the

\footnotetext{
${ }^{1}$ Verfassung des Kantons Zürich (27.02.2005), Chapter 2, Page 3, Art. 12. http://www.zhlex.zh.ch/Erlass.html?Open\&Ordnr=101.

${ }^{2}$ DSGS is one of three sign languages in Switzerland: LSF - Langue des Signes Française, LSI - Lingua dei Segni Italiana.

${ }^{3}$ Cf. Schweizerischer Gehörlosenbund, http://www.sgb-fss.ch/ (in Swiss German Sign language, Swiss French Sign language and Swiss Italian Sign language plus German, French and Italian).
} 
introduction and implementation of sign language teaching and learning using the systematics of the CEFR.

In the following sections, we first discuss the implications of CEFR for sign language (section 2), and make particular reference to our exploratory pilot project on Swiss German Sign language (DSGS, section 3). We then relate recent insights from a survey regarding the European ECML agenda toward a CEFR sign languages (section 4). The need for further research and development projects on DSGS to better meet learners' demands is discussed (section 5). Finally, special treatment is given to the difficulties and challenges recognised and encountered in deaf-non-deaf collaboration so far.

\section{The Common European Framework of Reference (CEFR)}

In accordance with the EU Lisbon Strategy (cf. EC, 2013) on fostering lifelong learning and multilingualism in Europe, since 2001 language teaching, learning, and assessment have undergone a change toward a learner-centred approach that is aiming at linguistic, pragmatic and sociolinguistic competencies. These competencies are described in the CEFR, a common manual originally instigated by the Swiss National Science Foundation (SNF) in the 1990s, and created and implemented by the Council of Europe in 2001 (cf. CoE, 2012).

The CEFR distinguishes three stages of progressively competent language use described as basic user (referring to proficiency levels A1, A2), independent user (proficiency levels B1, B2) and proficient user (proficiency levels $\mathrm{C} 1, \mathrm{C} 2$ ). These are clarified and condensed in a global scale which defines the levels by 'can do' descriptors and which constitutes the common reference levels.

If we look at the global descriptors for proficient users $(\mathrm{C} 1, \mathrm{C} 2)$, it becomes clear that interpreters need to function at level C2: "Can understand with ease virtually everything heard or read. Can summarize information from different spoken and written sources, reconstructing arguments and accounts in a coherent presentation" (cf. Little, 2006: 168, quoting the English Council of Europe publication of the CEFR from 2001).

In particular, the ability to give summaries or concise accounts of someone else's contribution are competencies many native speakers may have difficulties with, thus setting high standards for teaching, learning and assessment for foreign language learners who are aiming to become an interpreter.

The global scale on communicative language activities pertains to linguistic reception, production, interaction and mediation. However, the international consensus reflected in the CEFR only describes activity and process-oriented competencies that relate to reading, listening, spoken production and interaction, and written production, leaving mediation aside (cf. Little, 2006: 168). This means that specific linguistic competencies relating to mediating, which are needed when interpreting between languages, have been disregarded in the 'can do' descriptors up to now.

Yet, considering their minority status within a spoken language society, sign language users need access to mediation in everyday life. This may extend beyond what speakers of spoken languages encounter when they are in need of mediation (e.g. migrant workers, refugees and foreign students): interpreting poses an everyday necessity for Deaf sign language users, enabling them to participate in society. This demand in the marketplace also creates a strong incentive for interpreting as a career prospect for future learners studying sign language. As a consequence, clarification of 
mediation-related 'can do' descriptors is particularly urgent for sign languages and interpreter training.

This presupposes, of course, a CEFR for sign languages. Such a framework will facilitate and standardize learning, teaching and assessment of sign language competencies. Within the scope of the existing CEFR, the levels and achievements in language learning has been recognised, but has focused on activities that are strongly if not exclusively conceptualised from the perspective of spoken languages. Aspects relating to the specific modality of a sign language, e.g. the use of space, visualizing, fingerspelled alphabet, video based media literacy, etc. which are crucial to sign languages in general, are not integral components of the CEFR and thus are not captured in descriptors.

Not only with regard to their linguistic conditions of production, reception and mediation, sign languages are set apart from spoken languages. Sign languages are minority languages embedded in but often not (fully) recognised by their respective host society. This leads to the emergence of pragmatic and sociolinguistic features in sign languages that respond to societal marginalisation and that reflect partially in several aspects of the Deaf culture. In particular, sign language communities are known to develop communication patterns and strategies over time reflecting their exclusion from the oral/aural linguistic majority.

One case in point is the linguistic creation, control and communication of unity and closeness within the sign language community (termed "Verbundenheit" in Uhlig, 2012: 124-126). These sociolinguistic and pragmatic features in sign languages are in response to the needs of Deaf people living in a wider hearing society with limited knowledge about sign language. Hence, knowledge of linguistic means expressing a kind of 'unity principle' is required and constitutes pragmatic competency in sign language. For example, one needs to know and be able to express one's schooling and peer background and social relationships. This relates to discourse competency rather than knowledge of particular speech acts or expressions (cf. CEFR section 5.2.3).

Also, with regard to Grice's cooperation principle, which in the CEFR forms a pillar measurement of efficient and cooperative action (cf. CEFR section 5.2.3.1), problems arise: politeness conventions are stated explicitly as undermining the basic conversational maxims according to Grice with regard to the cooperation principle (cf. CEFR section 5.2.2.2). In sign language, pragmatic and sociolinguistic characteristics may well have a systematic impact, e.g. on linguistic marking of social relations in interaction. If sign languages tend to follow principles which are different from spoken languages in order to create cooperation, these would have to be established as specific sets of sociolinguistic and pragmatic competencies in a CEFR for sign languages.

In sum, in order to be able to use the CEFR as an instrument in teaching, learning and assessing communicative competencies in sign language as a foreign language, numerous adaptions towards sign language specific descriptors are called for. Essential domains for adaptation we have identified so far are:

(i) linguistic devices corresponding to reading and writing production in spoken languages;

(ii) sociolinguistic context embedded in a spoken language society;

(iii) pragmatic patterns peculiar and relevant to the sign language community;

(iv) mediation needs between sign language and spoken language users as well as between different sign languages.

Based on ongoing research in Europe's sign language communities, necessary adaptions and their implementation along the lines discussed 
above have been considered by several projects on a national scale in Europe. In Switzerland, the amount of work required in order to carry out an adaptation of CEFR to the three Swiss sign languages became clear over the past three years.

\section{CEFR-Sign languages: Starting points and preliminary insights}

Early on, between 2008 and 2010, the co-teaching process between $\mathrm{HfH}$ and ZHAW in the Swiss German sign language (DSGS) interpreting curriculum revealed that certain aspects of Swiss German Sign Language are not yet taught systematically. One case in point, where insecurities of the students made us aware of uncovered sociolinguistic and pragmatic topics, is the use of politeness and the variation of registers in DSGS.

To cite an example, Standard German works on the basis of a compulsory $\mathrm{T} / \mathrm{V}$ division, i.e. a distinction between the ' $\mathrm{T}$ '-register, from French "tu", German "du", denoting familiarity and an established relationship of mutual trust in opposition to a ' $\mathrm{V}$ '-register, from French "vous", German plural 3rd person "Sie", denoting official relations or unfamiliarity of the interlocutors with each other. Swiss German, in turn, tends to use T-address more often and sooner in forging relationships than Standard German; and both DSGS and Standard German are conceived to express more 'direct' forms of addressing interlocutors and problems arising in interaction, than is the custom in Swiss German communication.

Thus, for students of DSGS, the Swiss situation of diglossia between Standard and Swiss German varieties creates an ambiguity: whereas lip movement in DSGS is mostly oriented towards the Standard German, pragmatics, as the situational choice of register or terms of address, are clearly embedded in and dependent on the Swiss German society.

Addressing these interdependencies between at least three languages and varieties in an interpreter education program can explain and clarify the differences for the learners thereby resolving the issue of ambiguity. We could come up with several very straightforward 'can do' descriptors to cover this particular sociolinguistic and pragmatic aspect of competency.

What the above example illustrates is that in order to formulate 'can do' descriptors for DSGS, it might be advantageous to take into consideration means of comparative linguistics and pragmatics. To do so, we need more research identifying areas where learners and interpreters are confronted with challenges and ambiguities. Moreover, close collaboration by Deaf DSGS instructors and users with Deaf and non-deaf researchers is a prerequisite for analysing and explaining the specific ambiguities and deriving comprehensive 'can do' descriptors.

In a first attempt, the Swiss National Foundation (SNF) Doing Research (DoRe) project proposal in 2010-2011, took concrete steps to forge collaboration between the Deaf and non-deaf researchers in working together for that common cause and goal. After the head of the SGB-FSS sign language section, Brigitte Daiss-Klang, was drawn into the project, she also brought in her DSGS instructors to join the research discussions.

The DoRe authorities decided not to fund our preliminary project, so we continued to cooperate with the SGB-FSS to implement our own preliminary study in order to understand how the CEFR system functions and what it would mean for sign language learning, teaching and assessment.

Even though the first research proposal proved unsuccessful, it was the starting point which led to a pilot project financed by the Swiss Federation of the Deaf (SGB-FSS) in 2011-2012 (Shores et al., 2012), and two further joint research proposals which are currently underway. The pilot project was 
carried out by Deaf SL instructors together with non-deaf linguists under auspices of the Swiss Federation of the Deaf (SGB-FSS), HfH and ZHAW.

A large part of the pilot project was dedicated to mediating the values and concepts behind CEFR for the involved Deaf SL instructors to turn them into researchers. This was crucial, as all future projects will have to rely on both shared knowledge on research processes as well as the CEFR, its terms and concepts. The Deaf SL instructors-turned-researchers were charged with the compilation of existing DSGS teaching materials and assessing these with regard to linguistic subjects, pragmatic and sociolinguistic topics, and possible grading in terms of CEFR levels.

These findings were discussed subsequently in several research meetings over a period of roughly one year. Also, a network was formed with researchers working on German sign language (DGS), with Christian Rathmann and his team at the University of Hamburg. Research discussions with our network partners revealed in part diverging assessments of CEFR levels, e.g. with regard to the fingerspelled alphabet as a prerequisite means and auxiliary device to sign languages.

It was also clear though this process that different approaches were preferred by the different research teams. While Christian Rathmann and his team graded linguistic subjects and pragmatic and sociolinguistic topics in a top-down manner, based on analytic categories they had derived from years of experience with teaching German Sign Language DGS at university level in Hamburg, our team set out to evaluate the DSGS data empirically, analysing and assigning the levels in a bottom-up manner. Both approaches have their advantages. However, ultimately, both approaches are needed in order to control and compare findings and analyses cross-sign-linguistically, before forming descriptors and assigning CEFR levels.

The findings in our pilot project show that already at the 'Breakthrough', 'Waystage' and 'Threshold' levels (A1, A2, B1, cf. Little, 2006: 174-175) a considerable number of topics were related to pragmatic and intercultural aspects of DSGS, which are not yet explicitly documented in the teaching materials. Upon cross-referencing our findings with the CEFR it became clear that several aspects, e.g. the example on address terms and register discussed above, also call for an elaboration of the CEFR descriptors (cf. Shores et al., 2012).

In the pilot project we covered only material at the beginner and advanced beginner levels. At levels B1-B2 (independent user) and levels C1$\mathrm{C} 2$ (proficient user), more demanding competencies are expected, especially regarding the discourse and text production and interaction skills. Since these skills involve intimate situational knowledge of Deaf community interaction and the expression of communion, substantial gaps in the existing CEFR descriptors are predictable, suggesting a clear need for 'can do' descriptors for sign languages. These will have to be the object of further study, and are topics of current research (cf. Keller et al., 2013).

On the whole, current DSGS standards in training denote certain shortcomings of competencies in DSGS as a second language up to now. Despite DSGS being taught by Deaf sign language instructors, sociolinguistic and pragmatic standards reflecting the practices of the Deaf community are still lacking in DSGS training. This situation calls for community based research on the linguistic practices embedded in the DSGS community and its domains.

A continuing need for research (cf. Bangerter, 2013; Boyes Braem et al., 2012; Uhlich, 2012) lies in adapting unified standards according to the CEFR, and in developing and providing a European Language Portfolio (cf. ELP 2010; Little, 2006: 182-186) which describes learners' abilities and competencies, rather than focusing on their deficiencies (cf. Haug \& Keller, 2011). One of the results of our joint pilot project is the natural emergence of 
collaboration between Deaf and non-deaf researchers and professionals in the field. It will serve as a basis for our ongoing efforts in DSGS standardisation and help foster the professionalisation among Deaf SL instructors and SL interpreters.

\section{The European context: ECML and the PRO-Sign project}

In addition to the exchange with the German project aiming at a CEFR adaptation to German sign language (DGS), a network within Europe was started. European projects working on a national CEFR for sign language were contacted in order to compare methods, focal points and present state of their work. A preparatory European Science Foundation (ESF) workshop held at HfH Zurich in September 2011 became the first step to coordinate European endeavours concerning various European sign languages.

The ESF Workshop resulted in a comprehensive agenda bringing together efforts ranging from Swiss DSGS and LSF to German, Austrian, French, Belgian, Irish, British, Italian and Spanish sign languages (cf. Haug $\&$ Keller 2011). It set the foundation for a more coordinated operation under the auspices of the Council of Europe's language division, the European Centre for Modern Languages (ECML). ${ }^{4}$

The ECML was set up in 1994 in Graz, Austria, to serve the needs of 32 member states ${ }^{5}$ of the Council of Europe. It aims to reinforce language education and respect for the cultural and linguistic diversity in Europe, in order to advance a common understanding as the basis for peaceful and multicultural European societies. The ECML focuses on bridging the gap between language policy theory and classroom learning practice. Its objectives are to promote intercultural dialogue, democratic citizenship and human rights, and excellence in language education.

The 2012-2015 program emphasizes the learner as the key agent who ideally has a lifelong learning approach based on formal, informal or nonformal learning, and who ultimately will be responsible for fostering positive and productive multicultural societies. ${ }^{6}$ Irrespective of the learner's background in in a majority or minority population, as a migrant or nonmigrant, with and without special needs, as a national, regional or nonterritorial language speaker, the learner is entitled to quality education. In the ECML vision this means inclusive, plurilingual and intercultural education.

Signed languages were not specifically promoted in the context of the ECML. In 2012, as an outcome of the 2011 ESF workshop, the PRO-Sign project proposal by Lorraine Leeson (Ireland, ISL), Tobias Haug (Switzerland, DSGS), Christian Rathmann (Germany, DGS) and Beppie van den Bogaerde (Netherlands, NGT) was approved and is currently in the stage of implementation (cf. Shores et al., 2013; ECML, 2012-2015). The approval was a European milestone for the sign language communities, and an encouragement to start working and envisaging European excellence in sign language learning, teaching and assessment.

\footnotetext{
${ }^{4}$ refer to http://www.ecml.at

${ }^{5}$ Albania, Andorra, Armenia, Austria, Bosnia and Herzegovina, Bulgaria, Croatia, Cyprus, Czech Republic, Denmark, Estonia, Finland, France, Germany, Iceland, Ireland, Latvia, Liechtenstein, Lithuania, Luxembourg, Malta, Montenegro, Netherlands, Norway, Poland, Romania, Slovak Republic, Slovenia, Spain, Sweden, Switzerland and the former Yugoslavia Republic of Macedonia.

${ }^{6}$ European Centre for Modern Languages 2012-2015 Programme Broschure, Learning through languages. Promoting inclusive, plurilingual and intercultural education. Graz: European Centre for Modern Languages. p.12 [http://www.emcl.at/learningthroughlanguages]
} 
In a four-year period from 2012 to 2015 , the PRO-Sign project ${ }^{7}$ aims to establish European standards in sign language proficiency for professional purposes, for sign language teaching in Deaf Studies and sign language interpreting programs. These will be elaborated in accordance with the Common European Framework of Reference (CEFR) and its respective proficiency levels.

Five outputs from this project are planned, including the definition of proficiency levels for sign languages. Others are the development of curricula for hearing learners of sign languages; teaching and learning guidelines; and a draft of the European Language Portfolio for sign languages. A sample assessment kit for sign language competency at the highest levels $\mathrm{C} 1-\mathrm{C} 2$ for the qualification of professional interpreters is also being planned.

Three project outcomes aim to provide guidance and a standard level of expected proficiency for the Deaf communities and employers of sign language interpreters to depend on. With the help of these guidelines and standards, teachers and lecturers will be able to benchmark sign language curricula across Europe and to benefit from networks of shared practice.

In order to involve the Deaf communities and researchers who are Deaf from the time of launching the PRO-sign project, a first European workshop took place at the ECML on 15th to 17th April 2013. Appointed representatives from 30 ECML Member States were sent by their national contact coordinators to attend as national representatives for their respective countries and to get acquainted with the European project. Switzerland selected Patty Shores to attend the PRO-sign project. At the workshop, the ECML, its mission and goals were presented and the PRO-sign team introduced the project in front of all European member state representatives, including a new representative from Moscow University, representing Russia.

To begin with, the results of a preliminary online survey were shared for the first time by Tobias Haug, prior to the workshop ${ }^{8}$. The survey investigated the use and implementation of the CEFR in programs for sign language interpreters or Deaf Studies across Europe. The survey also collected data on how sign language assessment of the learners took place in each country; 53 European representatives out of 59 responded (six were from other countries such as China and USA). Out of the 53 reporting countries, 23 countries $^{9}$ participated in this survey. Selected findings are summarised in the Table 1 (cf. Haug et al., 2013).

The CEFR (for spoken languages) is used in most of the Council of Europe's member states, although it is not acknowledged as a guideline for language learning, teaching and assessing for all purposes (e.g. it is less useful for persons with little educational background).

\footnotetext{
${ }^{7}$ PRO-sign, Signed languages for professional purposes in the ECML Languages 2012-2015 Programme Broschure, Learning through languages Promoting inclusive, plurilingual and intercultural education. Graz: European Centre for Modern Languages. p.25 [http://www.emcl.at/learningthroughlanguages]

${ }^{8}$ A summary of the conference and the presentation in various sign languages is available at the CEFR4sl.eu web site. Publications based on the survey are currently in preparation (personal communication, Tobias Haug, 29.08.2013).

${ }^{9}$ Austria, Belgium, Bosnia \& Herzegovina, Czech Republic, Denmark, Estonia, Finland, France, Germany, Greece, Iceland, Lithuania, Malta, Netherlands, Norway, Poland, Romania, Slovenia, Spain, Sweden, Switzerland, Turkey and United Kingdom.
} 
Table 1: Summarised results from preliminary survey

a. Institutional/ Organisation Familiarity with CEFR -

16 know to a great extent.

15 know it somehow.

06 now it very little

06 do not know it at all.

b. Institutional/ Organisational implementation of CEFR -

18 implements.

19 do not implement at this stage.

16 write no answer.

out of the 19 not implementing the CEFR, their rationale was

07 do not know that at all.

07 in process to implement/develop.

05 do not have interest or use other framework.

c. Individuals using the CEFR -

15 Sign language teachers

02 Teacher trainers.

06 Interpreter trainers

04 Students

04 Test Developers

09 Material Developers

01 Spoken language teachers

01 Language tutors

08 Sign language teachers and material developers

06 Sign language teachers and Interpreter trainers

d. Translation of the CEFR into Signed languages-

04 Yes

33 No

If yes, which country?

1 from Austria

1 from Estonia

1 from France

1 from Spain

e. Further Plans for Translations of CEFR into Signed Languages -

17 Yes

06 No

29 No answer

01 No funds

The results in Table 1 reflect the current status of European standards in SL teaching, learning, and assessment with respect to the CEFR: while 16 members of the European Council's language division know the CEFR well and are working with it, the vast majority have insufficient knowledge with regard to CEFR, and are not currently interested in the CEFR and a SL adaptation. Those who already use it are mainly SL teachers, instructors, trainers and material developers.

Students have to date rarely made use of the CEFR. Additionally, only a very small number of countries have translated the CEFR into SL so far (4 out of 53). Roughly $30 \%$ of the members are interested in adapting the CEFR to SL. These results indicate that in Europe, among ECML members, 
concerns about the standardisation of SL learning, teaching and assessment are gaining momentum, even though the majority of member states and languages are not yet involved in CEFR adaptation.

Further steps were taken at the ECML workshop in terms of learning how to formulate the learning outcomes at the CEFR levels C1-C2 (for those who had experience). And those new to the CEFR were able to gain a basic orientation of levels A1-A2 descriptors. In between, informal networking of all representatives took place during breaks, meals and get-together events.

The last workshop event was focused on how we could disseminate our newly acquired knowledge and how we could then start the first steps in our respective countries. The ECML outlined different possibilities of working within our individual countries by contacting our national contact persons who are involved in programs conducting sign language teaching, learning and assessment. The outcome of these efforts and the 2013-2014 national and regional activities and new findings will be shared at a conference event in autumn 2014 at the University of Hamburg, Germany.

\section{Planned research and the Swiss-wide training project/s}

With the cooperative efforts taking place with the current European PROSign project, another community-based project including researchers who are Deaf and non-deaf in Switzerland is underway. It focuses on those aspects of sign language where descriptors of competencies are substantially different from spoken languages. Deaf researchers and participants will be involved in all stages from surveys regarding DSGS use, to data collection and analysis.

Additionally, traditional teaching and learning methods are being challenged by evolving new media such as internet based video news, video podcasting etc. which facilitate access to sign language materials as well as contact with and between sign language users.

A further, second project will focus on the development of selfassessment materials in accordance with ELP, employing an internet-based system and e-learning tool. That project is in preparation as collaboration between the HfH (Patty Shores) and ZHAW university colleagues (Christiane Hohenstein and Joerg Keller) in cooperation with University of Hamburg (Christian Rathmann and team) and the University of Maribor, Slovenia (Matjaz Debevc and team). It is anticipated that the Swiss Federation of the Deaf will be involved in this project too.

Results from these European and national projects will permit the development of unified teaching materials, of standardised assessments and provide a basis not only for the purposes of foreign language learning and interpreter training, but also for fostering the development of a CEFR for Sign Languages in Europe and Switzerland.

\section{Identification and recognition of special needs for successful collaboration between Deaf and non-deaf researchers}

Close cooperation, both by Deaf and non-deaf researchers and freelance collaborators as well as with the respective sign language communities and their institutions, will be crucial to successful CEFR adaptations in Europe. However, the same pragmatic and sociolinguistic characteristics of sign languages that need to be addressed in terms of 'can do' descriptors may actually emerge as cultural differences in research collaboration between the Deaf and non-deaf. 
Collaboration processes are invariably complex and based on the stakeholders' heterogeneous needs and goals. Transforming these into joint goals in the collaboration process is challenging even without lingua-cultural differences between the team members. Recognition and awareness of cultural differences and similarities between the members of the research team render the process possible, but not easy.

Cultural differences, with an example, of a preference for frequent faceto-face personal communication on work topics vis-à-vis a predilection for detailed written information and impersonal distribution; differences in the manner of contacting and the significance of the mode of communication chosen for formal and informal team communication is needed to be acknowledged in the first place, in order to be tackled.

Also, active consciousness of including the members of the sign language communities in the research and development activities is an important component of success to community-based research. This entails planning in advance face-to-face events on a regular basis and providing video summaries in sign language of all events and stages, which are accessible via internet. Consequentially, the means and resources needed simply to make communication work require serious planning ahead, both in terms of time and financial support.

\section{Conclusion}

The ongoing cooperation between the Deaf and non-deaf research collaborators contributes significantly to a new definition of boundaries within the sign language communities of Switzerland. The contributions from the present Pro-sign project and the Swiss German research projects foster an inclusion of scientific knowledge in sign language teaching, interpreting, and assessment. 


\section{References}

Bangerter, T. (2013). Ausführungsvarianten während formellen Anlässen: eine Analyse für die Deutschschweizer Gebärdensprache.

Bachelorarbeit Hochschule für Heilpädagogik Zürich, Online-Datei, 1 CD-ROM (158 S.) Referentinnen: Patty Shores, Heidi Stocker. Zürich: Interkantonale Hochschule für Heilpädagogik Zürich, Dept.2, Studiengang Gebärdensprachdolmetschen. Retrieved from http://www.rechercheportal.ch/zbz/action/search.do?dscnt=0\&vl\%2821 3214094UI0\%29=any\&scp.scps=scope\%3A\%28ebi01_prod\%29\%2Csc ope\%3A\%28retroseals\%29\%2Cscope\%3A\%28ZORA\%29\%2Cscope\% $3 \mathrm{~A} \% 28 \mathrm{UZH} 04 \% 29 \& \mathrm{frbg}=\& \mathrm{tab}=$ default_tab\&dstmp $=1377352959389$ $\&$ srt=rank \&ct $=$ search \&mode $=$ Basic $\& d u m=t r u e ~ \& \mathrm{tb}=\mathrm{t} \& \mathrm{ind} \mathrm{x}=1 \& \mathrm{v} 1 \% 28$ 1UIStartWith0\%29=contains \&v1\%28freeText $0 \% 29=$ tamara+bangerter

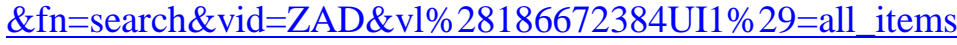
[26.08.2013].

Boyes Braem, P., Haug, T., \& Shores, P. (2012). Gebärdenspracharbeit in der Schweiz: Rückblick und Ausblick. In DAS ZEICHEN 90/2012, Zeitschrift für Sprache und Kultur Gehörloser. Retrieved from http://www.sign-lang.uni-hamburg.de/signum/zeichen/, S. 58-74.

CEFR Common European Framework of Reference for Languages: Learning, Teaching, Assessment. Retrieved from http://www.coe.int/t/dg4/linguistic/Source/Framework_en.pdf [08.08.2013]. [In German: GER Gemeinsamer europäischer Referenzrahmen für Sprachen: Lernen, lehren, beurteilen. Retrieved from http://www.goethe.de/z/50/commeuro/50202.htm [31.03.2013].

CoE Council of Europe (2012). Education and Languages, Language Policy. Retrieved from http://www.coe.int/t/dg4/linguistic/Cadre1_en.asp [09.08.2013].

Constitution of Canton Zurich (2005). Verfassung des Kantons Zürich 27.02.2005. Retrieved from http://www.zhlex.zh.ch/Erlass.html?Open\&Ordnr=101[18.08.2013].

EC European Commission (2013). Education and Training: Lifelong Learning Policy. Strategic framework for education and training. Retrieved from http://ec.europa.eu/education/lifelong-learningpolicy/framework_en.htm [10.08.2013].

ELP (2010 [2001]). European Language Portfolio (2010 [2001])/ ESP Europäisches Sprachenportfolio. Retrieved from http://www.languageportfolio.ch/page/content/index.asp?MenuID=2489 $\& \mathrm{ID}=4176 \&$ Menu=17\&Item $=6.1 .5$ [14.06.2013].

Haug, T., \& Keller, J. (2011). ESF Exploratory Workshop on Development of Theoretical and Practical Guidelines for the Adaptation of the Common European Framework of Reference (CEFR) to Sign Languages. Scientific Report. Zürich: Interkantonale Hochschule für Heilpädagogik und Zürcher Hochschule für angewandte Wissenschaften. Retrieved from http://www.HfH.ch/webautordata/70/10_112_Report.pdf [14.06.2013].

Haug, T., \& Shores, P. (2011). Tagung „,25 Jahre Gebärdenspracharbeit in der Deutsch Schweiz - Rückblick und Ausblick“, Mai 2011 (Conference on Sign language works in the German Switzerland). Zürich: Hochschule für Heilpädagogik (HfH).

Haug, T., Leeson, L., Rathmann, C., \& van den Bogaerde, B. (2013). CEFR for Signed Languages European Programme. Retrieved from http://cefr4sl.eu). [20.01.2014].

Keller, J., Hohenstein, C., \& Shores, P. (2013). Gemeinsamer Europäischer Referenzrahmen für Gebärdensprachen: Empirie-basierte Grundlagen für grammatische, pragmatische und soziolinguistische Deskriptoren in 
Deutschschweizer Gebärdensprache. Swiss National Foundation Research Projektantrag. Winterthur: ZHAW Angewandte Linguistik.

Little, D. (2006). The Common European Framework of Reference for Languages: Content, purpose, origin, reception and impact. State-ofthe-art article. Language Teaching 39, 167-190.

DOI:10.1017/S0261444806003557 Cambridge University Press, UK.

Little, D. (2011). Thinking allowed. The Common European Framework of Reference for Languages: a research agenda (PDF Manuscript). Dublin, Ireland: School of Linguistic, Speech and Communication Sciences, Centre for Language and Communication Studies, Trinity College, Dublin.

PRO-Sign - Signed Languages for Professional Purposes, European Centre for Modern languages (ECML), Graz. Retrieved from http://www.ecml.at/F5/News/tabid/881/language/en-GB/Default.aspx [15.06.2013].

Shores, P., Haug, T., Hohenstein, C., \& Keller, J. (2012). D.23 GER Gebärdensprachen-Vorprojekt (2011-2012). Schlussbericht. HfH Zürich. Retrieved from http://www.HfH.ch/webautor-data/70/FinalBericht-D23-Vorprojekt-GER-GS -02112012.pdf [15.06.2013].

Shores, P., Martens-Wagner, J., \& Kollien, S. (2013). Zwei Veranstaltungen im Rahmen des PRO-Sign-Projekte in Graz, Österreich. In DAS ZEICHEN 93/2013, Zeitschrift für Sprache und Kultur Gehörloser (www.sign-lang.uni-hamburg.de/signum/zeichen/), S. 330-333.

Uhlich, A. C. (2012). Ethnographie der Gehörlosen. Bielefeld: Transcript.

UN (2008-2012). United Nations Convention on the Rights of Persons with Disabilities (2008-2012). Retrieved from http://www.un.org/disabilities/default.asp?id=150 [05.08.2013]. 